Cahiers $d u$ MONDE RUSSE

\section{Cahiers du monde russe}

Russie - Empire russe - Union soviétique et États indépendants

45/3-4 | 2004

Varia

\title{
P.S. Stefanovič, Prihod i prihodskoe duhovenstvo v Rossii v XVI-XVII vekah
}

Pierre GONNEAU

\section{(2) OpenEdition}

Journals

Édition électronique

URL : https://journals.openedition.org/monderusse/4173

DOI : 10.4000/monderusse.4173

ISSN : 1777-5388

Éditeur

Éditions de l'EHESS

Édition imprimée

Date de publication : 1 juillet 2004

Pagination : 624-626

ISBN : 2-7132-2009-2

ISSN : $1252-6576$

Référence électronique

Pierre GONNEAU, «P. S. Stefanovič, Prihod i prihodskoe duhovenstvo v Rossii v xvI-xvII vekah », Cahiers du monde russe [En ligne], 45/3-4 | 2004, mis en ligne le 16 juin 2009, consulté le 03

septembre 2022. URL : http://journals.openedition.org/monderusse/4173; DOI : https://doi.org/ $10.4000 /$ monderusse. 4173

Ce document a été généré automatiquement le 3 septembre 2022.

Tous droits réservés 


\title{
P. S. Stefanovič, Prihod i prihodskoe duhovenstvo v Rossii v XVI-XVII vekah
}

\author{
Pierre GONNEAU
}

\section{RÉFÉRENCE}

\section{P. S. STEFANOVIČ, Prihod i prihodskoe duhovenstvo v Rossii v XVI-XVII vekah (La} paroisse et le clergé paroissial dans la Russie des $\mathrm{XVI}^{\mathrm{e}}-\mathrm{XVII}{ }^{\mathrm{e}}$ siècles). Moscou, Indrik, 2002, $349 \mathrm{p}$.

Comme l'indique discrètement l'auteur dans son introduction, ce livre représente une avancée nouvelle dans un champ où les recherches ont connu une "longue interruption" (p.30) et où beaucoup reste à faire. À la croisée des chemins entre l'histoire de l'Église, l'histoire sociale et l'histoire des mentalités, cette étude de la paroisse et du clergé paroissial dans la Russie des xvie-XVIIe siècles est utile et intéressante. Élève de V.S. Šul'gin et B. N. Florja, P. S. Stefanovič a une connaissance très poussée de la bibliographie russe, principalement d'Ancien Régime, consacrée à son thème, mais il montre aussi une bonne ouverture sur les travaux en langues occidentales. Son terrain de prédilection est la bibliographie anglophone et il effectue un certain nombre de parallèles bienvenus avec la situation du clergé et des paroisses dans l'Église d'Angleterre. On aurait évidemment souhaité quelques références aux études sur la situation française (ne serait-ce qu'à travers les volumes de synthèse de l'Histoire du Christianisme, publiée sous la direction de Marc Venard, André Vauchez et al., chez Desclée), mais ce n'est pas le propos principal de l'auteur. On peut s'étonner, en revanche, de ne pas trouver mention de l'excellent livre de G. B. Michels (At war with the Church: Religious dissent in seventeenth-century Russia, Stanford, 1999) et de voir les sources étrangères concernant l'histoire de la Russie (Fletcher, Herberstein, Olearius) citées uniquement à travers des traductions russes. 
Les sources russes utilisées sont, elles, parfaitement maîtrisées. Il s'agit en premier lieu de la législation impériale et ecclésiastique, avec le fameux Concile des Cent chapitres (Stoglav, 1551), les actes du Grand Concile de 1666-1667 qui dépose Nikon et condamne les vieux-croyants, l'Établissement (Sobornoe Uloženie) de 1649, les autres édits et chartes du souverain, du patriarche, des synodes de l'Église russe. L'auteur nous présente aussi un corpus de documents d'archives à la fois riche et lacunaire. Les fonds des bureaux des administrations impériale et patriarcale sont mis à contribution. Les archives diocésaines russes ont, en revanche, souvent disparu, sauf en ce qui concerne les chaires de Novgorod, Ustjug, Vologda et Kruticy (Saraj). P. Stefanovič puise à ces sources, mais ne les exploite que sur une aire géographique réduite à la Russie centrale. En effet, en se fondant sur les travaux de ses prédécesseurs, il considère que les pays ruthènes (sur le territoire actuel de la Biélorussie et de l'Ukraine) et le Nord de la Russie forment, avec la Sibérie, des entités spécifiques où le mode de vie des communautés paysannes et des paroisses est nettement distinct de ce que l'on observe au centre de l'empire (p. 8).

Le propos de l'auteur se répartit en quatre grands chapitres. Le premier est consacré au patronat des laïques et à leurs droits de propriété sur ce que l'on appellerait en France les bénéfices ecclésiastiques. Le deuxième étudie les revenus du clergé. Le troisième présente le statut du clergé, sa constitution en tant qu'« état » (soslovie) de la société russe. Le dernier chapitre traite de l'organisation interne et de la vie de la communauté paroissiale. On ne saurait trop découvrir ou redécouvrir le rôle de "l'initiative privée " (p.6) dans la vie religieuse russe. Il est frappant de constater la permanence du patronat laïque - disparu en Occident aux XIIe-XIIIe s., en Pologne et en Bohême aux xiIIe-XIVe s. dans la Russie des Xvie-XviIe siècles (p. 29, 314). Néanmoins la période étudiée est aussi celle durant laquelle le clergé séculier se structure véritablement et la paroisse affirme son identité « en tant que communauté territoriale et religieuse » (p. 310).

Les décrets du Stoglav avaient déjà prévu de séparer nettement la sphère du clergé blanc et celle des fidèles, en particulier dans la gestion des biens et la juridiction des personnes, mais ils ne sont véritablement appliqués qu'au XVII siècle (p. 231-232). De même, c'est à partir de 1567 que commence à devenir de règle l'allocation d'un lopin de terre au prêtre de la paroisse, mais il faut attendre la fin du XVII ${ }^{\mathrm{e}}$. pour que l'Église contrôle réellement la gestion et la transmission de ce bien; en l'absence d'un prélèvement obligatoire pour l'entretien des prêtres, le lopin est leur principal moyen de subsistance (p. 167-168). La constitution de l'état clérical se systématise avec la promulgation du Sobornoe Uloženie. Les dispositions de ce code représentent un point d'équilibre entre l'affirmation de l'absolutisme monarchique et la reconnaissance des privilèges de chaque état, en particulier du clergé. Les réformes lancées par le Grand Concile de 1666-1667 contribuent aussi à une amélioration sensible du statut du clergé séculier. On ne peut donc affirmer, comme certains historiens de l'Église russe, que son asservissement à l'État était déjà en cours et que les réformes de Pierre le Grand ne firent que parachever un processus bien engagé. P. Stefanovič semble pourtant hésiter entre deux appréciations de la situation. D'une part, «à la fin du XvII siècle, l'Église russe est reconnue comme une institution complètement autonome et indépendante de l'État, avec son chef, ses lois, son administration et sa juridiction. Mais d'autre part, l'influence de l'État sur l'Église ne diminuait qu'en ce qui concernait les affaires internes de l'Église; par ailleurs, l'autorité de l'État se renforçait et, à la fin du xvII siècle, il s'apprêtait déjà à restructurer complètement ses rapports avec l'Église » (p. 232). 
Un autre point crucial, qui reste à approfondir, est celui de l'instruction du clergé. Les efforts entrepris à partir de 1666-1667 ont-ils vraiment porté leurs fruits au point de donner aux fidèles des pasteurs capables de leur dispenser une pastorale dans les règles (gramotno sostavlennuju propoved'), ou bien doit-on conserver l'image, bien ancrée dans les récits des voyageurs étrangers et dans les édits des monarques éclairés du siècle des Lumières, d'un clergé ignare (p. 317) ? Il reste à souhaiter que d'autres études de ce type viennent compléter et nuancer cet important travail. 